\title{
Vigas mistas de madeira de reflorestamento e bambu laminado colado: análise teórica e experimental
}

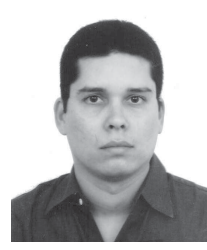

Humberto C. Lima Júnior ${ }^{1} \&$ Antônio A. Dias²

\begin{abstract}
1 UNIOESTE. R. Universitária, 2069, CEP 85814-110, Cascavel, PR. Fone: (45) 220-3221. E-mail: correialima@unioeste.br (Foto) 2 EESC, Universidade de São Paulo/USP. Av. Dr. Carlos Botelho, 1465, São Carlos, SP, CEP 13560-970, Fone: (16) $273-9479$. E-mail: dias@sc.usp.br
\end{abstract}

Protocolo $018-14 / 2 / 2001$

\begin{abstract}
Resumo: Neste trabalho, apresenta-se e se discute a análise teórica e experimental de vigas de madeira, reforçadas com bambu. Para tanto, o comportamento mecânico de cinco vigas mistas e duas de madeira foi estudado. A parte interna das vigas mistas foi constituída de Pinus elliottii e o reforço de bambu Dendrocalamus giganteus; este reforço foi disposto tanto na parte inferior como na superior das vigas, além de analisadas diferentes espessuras de reforço. São apresentadas curvas carga vs. deslocamentos e carga vs. deformação. Observou-se aumento da ordem de $50 \%$ na rigidez das vigas de Pinus elliottii, quando da presença do reforço de bambu. Finalmente, um estudo numérico em que se utilizou o método dos elementos finitos é apresentado, observando-se boa correlação entre os valores numéricos e experimentais.
\end{abstract}

Palavras-chave: estrutura, bambu, reforço

\section{Composite beams of reforestation wood and glue-laminated bamboo: Theoretical and experimental analyses}

\begin{abstract}
This paper presents and discusses the experimental and theoretical analyses of layer composite beams of wood strengthened with bamboo. For this, the mechanical behavior of five composite beams and two wood beams was studied. The beam's stuffing was composed of Pinus elliottii and the reinforcement of bamboo Dendrocalamus giganteus. The bamboo reinforcement was placed on the top and at the bottom of the beams. Different thicknesses of reinforcement were investigated. Curves of load vs. displacement and load vs. strain are presented. An increase of $50 \%$ was observed in the stiffness, when the composite beams are compared with the wood one. Finally, a numerical study was carried out applying the finite element method and a good agreement was observed between the theoretical and experimental values.
\end{abstract}

Key words: structure, bamboo, reinforcement

\section{INTRODUÇÃO}

O bambu é um material vegetal cujas propriedades mecânicas indicam grande potencial a ser explorado pela engenharia. A planta apresenta longos colmos, ocos no interior, os quais são fechados a intervalos mais ou menos regulares, por um diafragma nas regiões dos nós; suas paredes têm excelente resistência à tração e à compressão, comparáveis às mais nobres madeiras ressaltando-se, ainda, seu baixo peso específico, da ordem de $8,5 \mathrm{kN} \mathrm{m}^{-3}$. Apesar das formidáveis propriedades físicas e mecânicas aqui mencionadas, o bambu tem sido pouco utilizado como material na indústria da construção civil devido, basicamente, a dois fatores: à sua configuração geométrica, que impossibilita a confecção de peças estruturais usuais, como vigas e pilares de seções transversais retangulares e à sua baixa resistência ao cisalhamento, que não permite a cravação de pinos, tornando inviável o projeto de estruturas de maior porte, em que se necessite de emendas ou ligações.

Nos últimos anos, com a preocupação global de preservação ambiental e por ser um dos vegetais que mais rápido crescem no planeta (Culzoni, 1986) as indústrias orientais de móveis e de papel têm investido em tecnologia para o aproveitamento mais racional do bambu. Dentre tais indústrias destacam-se as de piso laminado de bambu, que atualmente produzem, em escala industrial, pisos laminados de alto padrão de acabamento. Analisando-se este processo industrial de laminação do bambu juntamente com o da madeira laminada colada (Bono, 1996) observa-se que eles podem ser aplicados na fabricação de peças estruturais de bambu laminado colado (BLC) associados à madeira de reflorestamento. A tecnologia do bambu laminado colado, basicamente elimina os problemas de cisalhamento e geometria, permitindo que este material tenha utilização mais racional na engenharia estrutural. 
Este trabalho procura mostrar a viabilidade técnica do uso do bambu em elementos estruturais, pelo processo de laminação. Para isso, foram confeccionadas e ensaiadas cinco vigas mistas de bambu Dendrocalamus giganteus associado à madeira de Pinus elliottii, com diferentes espessuras da camada de bambu. Um estudo numérico no qual se utilizou o método dos elementos finitos, também foi realizado, e mostra elevado ganho de rigidez nas vigas, quando do reforço de bambu. Finalmente, foi realizado um estudo experimental do cisalhamento, paralelo às fibras do bambu.

\section{MATERIAL E MÉTODOS}

\section{Bambu}

Utilizou-se bambu da espécie Dendrocalamus giganteus, obtido do Zoológico de Cascavel, PR, cujos colmos foram cortados com 2 e 3 anos de idade e deixados secar, à sombra, em temperatura ambiente, por um período de 2 meses. Com comprimento médio de $20 \mathrm{~m}$, os colmos foram divididos em três trechos de igual comprimento, denominados basal, intermediário e topo. Para os estudos apresentados neste trabalho, considerou-se apenas o trecho intermediário. A Tabela 1 apresenta as dimensões médias e os respectivos desvios-padrão dos colmos utilizados.

Tabela 1. Características físicas do bambu Dendrocalamus giganteus

\begin{tabular}{lrrr}
\hline \multirow{2}{*}{ Região } & Internódio & Diâmetro & Esp. Parede \\
\cline { 2 - 4 } & \multicolumn{3}{c}{$\mathrm{cm}$} \\
\hline Basal & $44,1-8,4$ & $17,2-1,1$ & $2,2-0,8$ \\
Intermediária & $52,4-2,0$ & $13,1-1,5$ & $1,6-0,5$ \\
Topo & $43,4-5,0$ & $9,2-2,8$ & $1,0-0,3$ \\
\hline
\end{tabular}

As propriedades mecânicas do bambu utilizado foram obtidas por Lima Jr. et al. (2000) e são apresentadas na Tabela 2, segundo os quais o bambu Dendrocalamus giganteus apresenta comportamento elástico linear até a ruptura, tanto a compressão quanto a tração.

Tabela 2. Propriedades mecânicas do bambu Dendrocalamus giganteus (Lima Jr. et al., 2000)

\begin{tabular}{lrc}
\hline Propriedades do Bambu & Sem Nó & Com Nó \\
\hline Módulo de elasticidade à tração $(\mathrm{GPa})$ & 23,75 & 13,14 \\
Resistência à tração $(\mathrm{MPa})$ & 277,19 & 97,51 \\
Módulo de elasticidade à compressão $(\mathrm{GPa})$ & 20,50 & 21,88 \\
Resistência à compressão $(\mathrm{MPa})$ & 56,65 & 57,99 \\
\hline
\end{tabular}

\section{Madeira}

A madeira utilizada como recheio nas vigas de bambu laminado colado, foi da espécie Pinus elliottii. Três vigas (R1, $\mathrm{V} 1 \mathrm{e}$ V2) foram confeccionadas de uma mesma peça de madeira e quatro vigas (R2, V3, V4 e V5) de outra. A umidade média das peças de madeira era de $11,7 \%$ e suas propriedades mecânicas foram obtidas através de corpos-de-prova extraídos de regiões não danificadas dos próprios espécimes após ensaio. Buscou-se manter as relações dimensionais dos corpos-de-prova sugeridas pela NBR-7190 Projeto de estruturas de madeira (ABNT, 1997). As médias das propriedades mecânicas das duas peças de madeira são apresentadas na Tabela 3.
Tabela 3. Propriedades mecânicas do Pinus elliottii Propriedades do Pinus elliottii

Tensão na flexão (MPa) (R1, V1, V2)

Rigidez na flexão (GPa) (R1, V1, V2) 68,8

Tensão na flexão (MPa) (R2, V3, V4 e V5)

Rigidez na flexão (GPa) (R2, V3, V4 e V5)

\section{Ensaio de cisalhamento paralelo às fibras do bambu}

Realizou-se ensaio de cisalhamento paralelo às fibras, em 10 espécimes. Os corpos-de-prova foram constituídos por 5 lâminas de bambu com $1 \mathrm{~cm}$ de espessura, coladas uma às outras, por adesivo à base de resorcinol; esses corpos apresentavam dimensões de $6,4 \times 5 \times 3 \mathrm{~cm}$. Buscou-se um plano de cisalhamento, de modo a não atingir o plano de cola. A Figura 1 apresenta as características dos corpos-de-prova idealizados para ensaio de cisalhamento, paralelo às fibras do bambu.
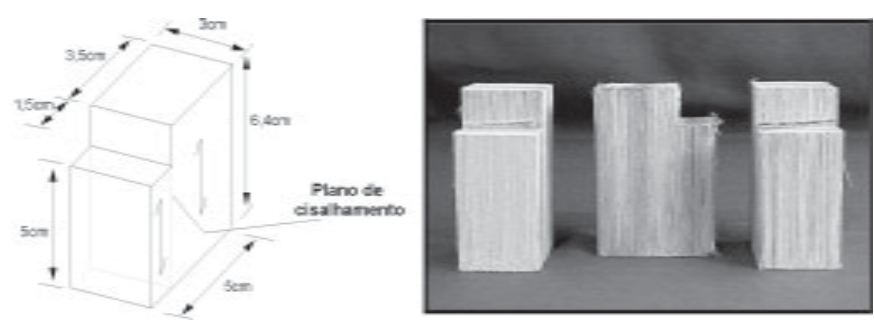

Figura 1.Características dos corpos-de-prova para o ensaio de cisalhamento paralelo às fibras do bambu

Os ensaios foram executados em uma máquina universal de ensaios, com controle de carga, seguindo-se os procedimentos de ensaio de cisalhamento estabelecido pela NBR-7190 Projeto de estruturas de madeira (ABNT, 1997). Na Figura 2 mostra-se sua montagem.

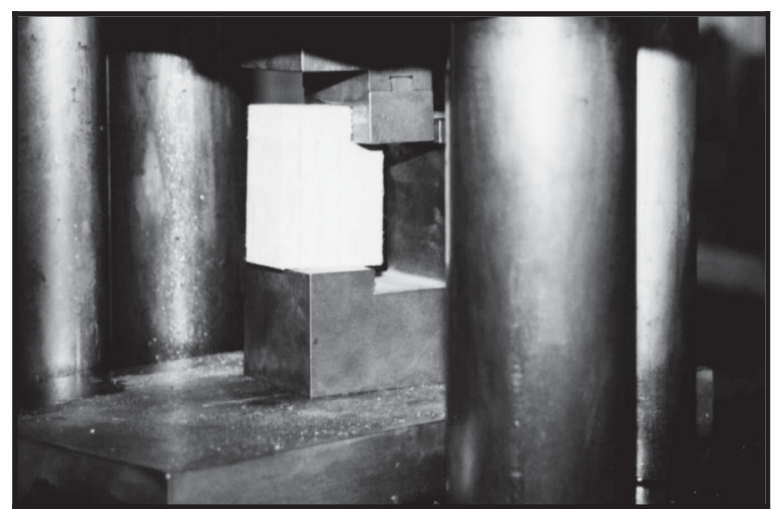

Figura 2. Montagem do ensaio de cisalhamento paralelo às fibras do bambu

\section{Ensaio das vigas mistas de BLC}

Para avaliação experimental do comportamento das vigas com bambu laminado colado, foram ensaiados sete espécimes, divididos em duas séries, em que os da série um e da série dois apresentavam dimensões de $3 \times 8 \times 100 \mathrm{~cm}$ e $3 \times 6 \times 100 \mathrm{~cm}$, respectivamente, enquanto dois, viga $\mathrm{R} 1$ e $\mathrm{R} 2$, foram confeccionados apenas com Pinus elliottii para servirem de referência àqueles reforçados com bambu. Os outros cinco espécimes apresentavam a parte central de Pinus elliottii e, na 
parte superior e inferior, tiras de bambu coladas com resina à base de resorcinol. As tiras de bambu apresentavam espessura de $5 \mathrm{~mm}$ e largura de $15 \mathrm{~mm}$ e foram dispostas duas a duas, em cada camada. Na primeira viga, V1, a parte central de Pinus elliottii foi confeccionada com $6 \mathrm{~cm}$ de altura e, em seguida, coladas duas camadas de bambu na parte inferior e duas na parte superior, totalizando $8 \mathrm{~cm}$ de altura; já na segunda, viga $\mathrm{V} 2$, a parte central tinha $5 \mathrm{~cm}$ de altura e coladas três camadas de bambu na parte inferior e três na parte superior totalizando, também, $8 \mathrm{~cm}$ de altura. Nas terceira, quarta e quinta vigas, V3, $\mathrm{V} 4 \mathrm{e} \mathrm{V} 5$, as partes centrais apresentavam $5,4 \mathrm{e} 3 \mathrm{~cm}$ de altura, respectivamente, e coladas camadas de bambu na parte inferior e superior, de modo a totalizar, no final, uma altura de $6 \mathrm{~cm}$. Nas vigas V1 e V2 buscou-se dispor a região nodal das tiras de bambu de forma simétrica e o mais distante do centro dos espécimes, ficando estas aproximadamente $25 \mathrm{~cm}$ para cada lado da seção transversal central da viga. Nas vigas V3, V4 e V5 a disposição da região nodal foi realizada de forma aleatória.

Os ensaios de flexão foram realizados em uma máquina universal de ensaios, com controle de carga. Nas vigas da série um (R1, V1 e V2) o carregamento foi aplicado em quatro pontos, nos terços médios e nas vigas da série dois (R2, V3, V4, e V5) em três pontos, deixando-se $5 \mathrm{~cm}$ para cada lado de apoio e as vigas com vãos livres de $90 \mathrm{~cm}$. Observa-se que, para o caso do ensaio em três pontos, não foi obedecida a relação altura/vão igual a 21, recomendada pela NBR-7190 Projeto de estruturas de madeira (ABNT, 1997) pois um dos pontos a serem avaliados era a ruptura ao cisalhamento das lâminas de bambu. As vigas foram instrumentadas com relógio comparador no trecho central do vão. Na viga $\mathrm{V} 2$ foram colados, ainda, extensômetros elétricos na parte superior e inferior do reforço de bambu. A Figura 3 apresenta o esquema de ensaio. Finalmente, o método dos elementos finitos foi utilizado como ferramenta para a análise dos resultados.

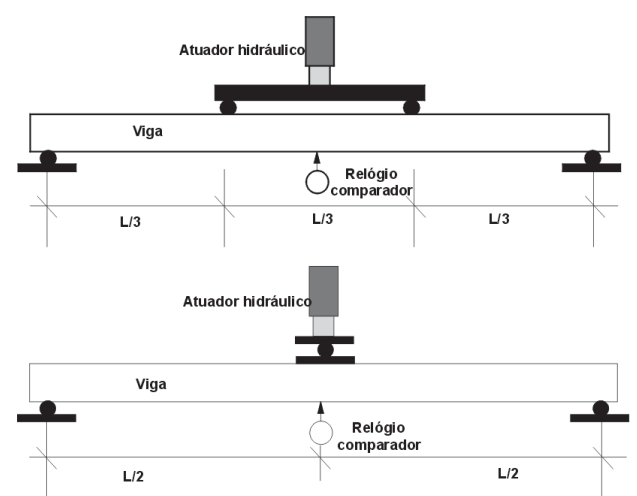

Figura 3. Montagem dos ensaios de flexão

\section{RESULTADOS E DISCUSSÃO}

\section{Tensão de cisalhamento paralelo às fibras do bambu}

Os corpos-de-prova apresentaram dimensões médias do plano de cisalhamento, de 50,5 x 30,7 mm; em todos eles, a ruptura se deu no plano predeterminado, isto é, distinto do plano de cola. A tensão média de cisalhamento com o respectivo desvio-padrão foi de 7,81 e 1,06 $\mathrm{MPa}$. Na Figura 4 apresentam-se detalhes da forma de colapso dos corpos-deprova.

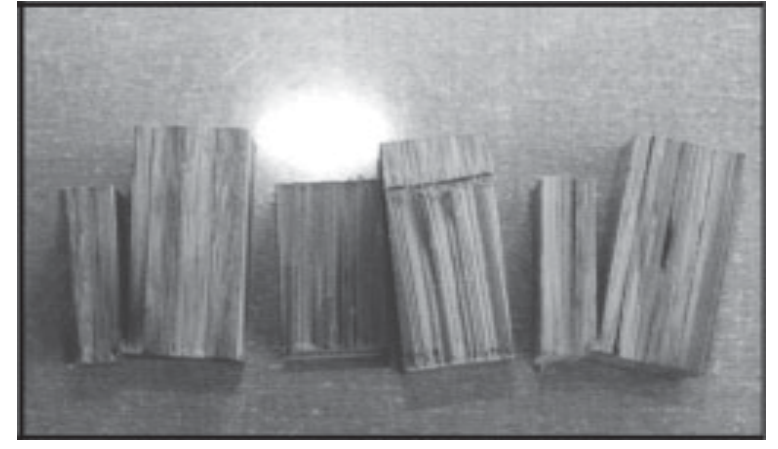

Figura 4. Modo de ruptura dos corpos-de-prova de cisalhamento

\section{Comportamento das vigas mistas de BLC da série um}

Com o objetivo de preservar a instrumentação, o relógio comparador foi retirado de serviço para o carregamento da ordem de $6 \mathrm{kN} \mathrm{e}$, em seguida, os espécimes foram levados à ruptura. As cargas de ruptura das vigas R1, V1 e V2 foram 16,0, 17,1 e 17,6 kN, respectivamente, enquanto a carga teórica da viga R1 era 14,7 $\mathrm{kN}$, significando uma diferença de aproximadamente $8 \%$ em relação à experimental. Não houve aumento significante na carga última dos espécimes com o aumento da espessura da camada de bambu, fato este devido aos diferentes mecanismos de colapso observados nos três espécimes e à disposição simétrica da região nodal do bambu, que provocou uma linha preferencial de ruptura. A ruína da viga $\mathrm{R} 1$ se deu por esmagamento das fibras comprimidas seguidas por ruptura brusca das fibras tracionadas.

$\mathrm{O}$ colapso da viga $\mathrm{V} 1$ ocorreu por ruptura à tração do bambu, na região nodal; entretanto, para o carregamento de colapso da viga $\mathrm{V} 1$, a tensão de tração correspondente nesta região era da ordem de $70 \mathrm{MPa}$, isto é, cerca de $30 \%$ inferior à resistência do bambu na região nodal. Essa ruptura prematura pode ter sido provocada pelo processo de laminação que, devido à geometria dessa região, provoca danos no bambu. Finalmente, a viga V2 atingiu a ruína por ruptura ao cisalhamento paralelo às fibras do reforço do bambu junto ao apoio. A tensão de cisalhamento máxima no bambu no instante do colapso da viga V2 era de $6,9 \mathrm{MPa}$, valor próximo à resistência obtida no ensaio de cisalhamento paralelo às fibras do bambu.

Utilizando-se a teoria clássica dos compósitos laminados (homogeneização da seção transversal) obtém-se que as cargas de colapso das vigas V1 e V2 para os modos de ruptura apresentados, são 24 e 20 kN. Nota-se certa discrepância entre os valores teóricos e experimentais, que pode ser explicado pela não consideração da plastificação do bambu na região comprimida e pela variabilidade das propriedades dos materiais. Na Figura 5 apresentam-se os detalhes do colapso dos três espécimes.

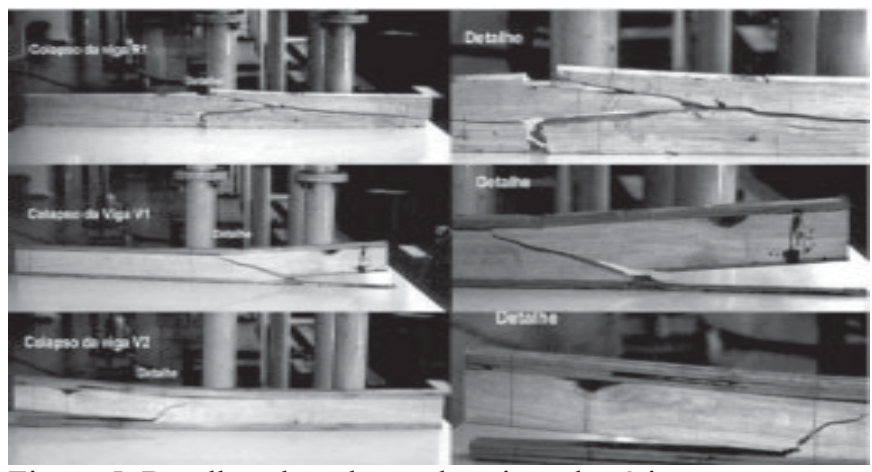

Figura 5. Detalhes do colapso das vigas da série um 
Na Figura 6 apresenta-se a curva carga vs. deslocamento central dos três espécimes ensaiados, observando-se aumento da rigidez à flexão com o acréscimo da espessura da camada de bambu. A viga $\mathrm{V} 1$ apresentou rigidez de cerca de $20 \%$ superior à da viga de referência e a viga V2 cerca de $50 \%$. Na Figura 7 apresenta-se a curva carga vs. deformações para a viga V2. Nota-se que as deformações de colapso nas fibras superiores e inferiores, são bem menores que as deformações de ruptura do bambu à tração e a compressão, de 10 e $20 \%$, respectivamente (Lima Jr. et al., 2000). Observa-se, ainda, comportamento carga vs. deformação quase linear até a ruptura da viga.

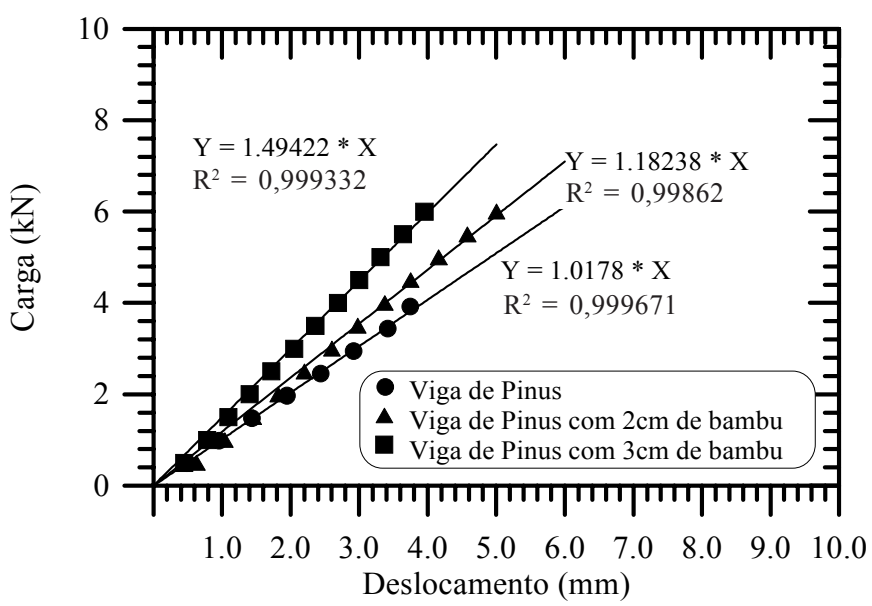

Figura 6. Curva carga vs. deslocamento vertical das vigas da série um

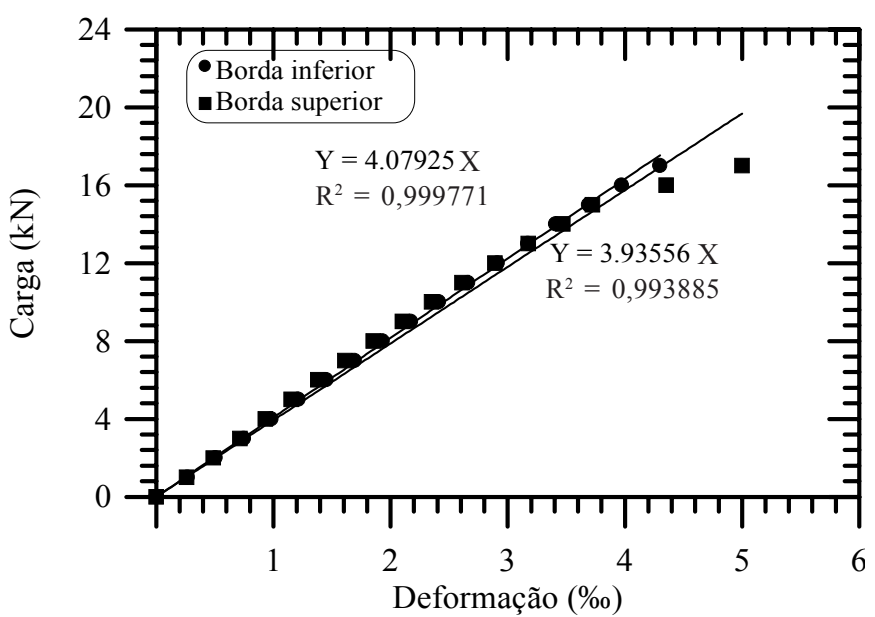

Figura 7. Curva carga vs. deformação das fibras inferiores e superiores, viga V2

\section{Comportamento das vigas mistas de BLC da série dois}

O procedimento de ensaio foi semelhante ao da série um, porém o relógio comparador só foi retirado de serviço para um deslocamento de $9 \mathrm{~mm}$. As cargas de ruptura das vigas R2, V3, V4 e V5 foram 3,1, 6,1, 6,7 e 8,4 kN, respectivamente, notando-se que a carga teórica da viga $\mathrm{R} 2$ era de $3,06 \mathrm{kN}$ e a diferença entre a carga experimental e teórica ficou da ordem de $1 \%$ e que, ao contrário da série um, ocorreu um ganho considerável de resistência nos espécimes com aumento da espessura da camada de bambu, chegando a $171 \%$ para a viga V5, ganho este que pode ser proveniente da disposição aleatória da região nodal das tiras.
A ruína da viga $\mathrm{R} 2$ se deu por ruptura brusca das fibras tracionadas e o colapso da viga V3 por ruptura a tração do bambu, na região do nó, enquanto a ruína da viga V4 também foi ocasionada por ruptura a tração do bambu, na região nodal; finalmente, a viga V5 atingiu a ruína por ruptura simultânea ao cisalhamento paralelo às fibras do reforço do bambu junto ao apoio e ruptura a tração do bambu na região nodal. As tensões no bambu nos pontos de ruptura para a carga de colapso da vigas V3, V4 e V5 foram de 67, 78 e $93 \mathrm{MPa}$, respectivamente; concluiu-se, portanto, que em todos os casos a tensão de tração de colapso foi inferior à resistência do material, fato este já explicado no item anterior; utilizando-se novamente a teoria clássica para se calcular as cargas de ruptura das V3, V4 e V5, para os modos de falha observados, tem-se que estas são de $8,03,7,3$ e $8,1 \mathrm{kN}$, respectivamente. A pequena diferença entre as cargas teóricas das vigas V3, V4 e V5 é justificada pelo posicionamento aleatório das regiões nodais do bambu. $\mathrm{Na}$ Figura 8 apresentam-se os detalhes do colapso dos espécimes da série dois, constatando-se que em todos os espécimes com reforço os modos de ruptura foram semelhantes.

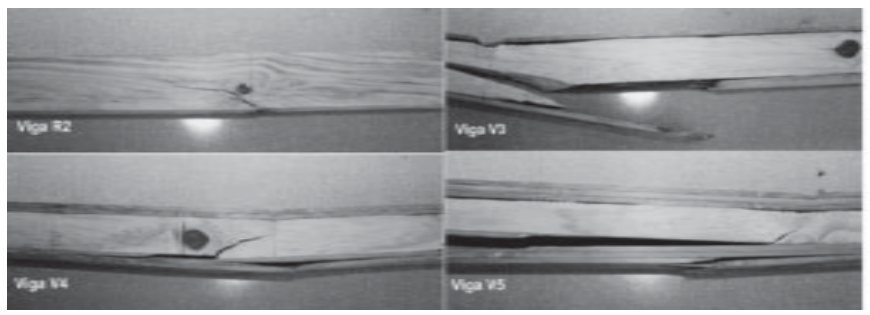

Figura 8. Detalhes do colapso das vigas da série dois

Na Figura 9 apresenta-se a curva carga vs. deslocamento central dos quatro espécimes ensaiados e nela se observa, também, o aumento da rigidez com o aumento da espessura da camada de reforço de bambu. As vigas V3, V4 e V5 apresentaram rigidez de cerca de 47,6, 72,4 e 91,6\% superior à da viga de referência, respectivamente; entretanto, o ganho de rigidez entre as vigas $\mathrm{R} 2 \mathrm{eV} 3, \mathrm{~V} 3 \mathrm{eV} 4$, e V4 e V5, vai decaindo.

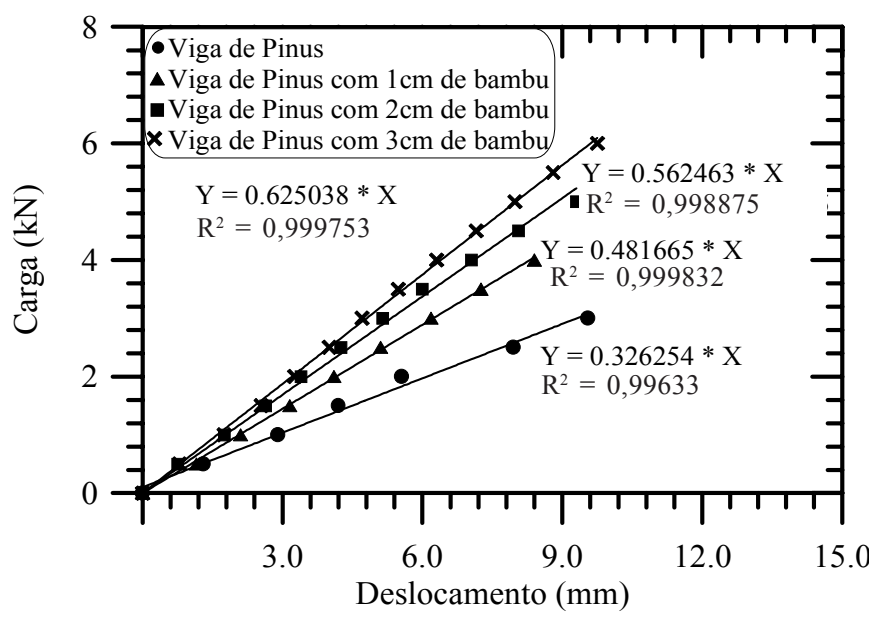

Figura 9. Curva carga vs. deslocamento central das vigas da série dois

\section{Estudo paramétrico via método dos elementos finitos}

Para avaliação do comportamento das vigas de BLC, estudaram-se diversos casos de vigas laminadas Dendrocalamus 
A.
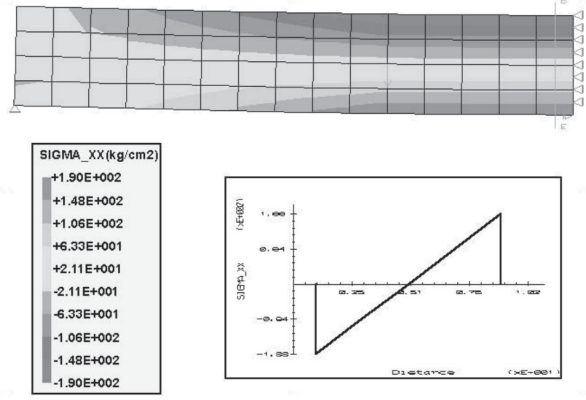

B.

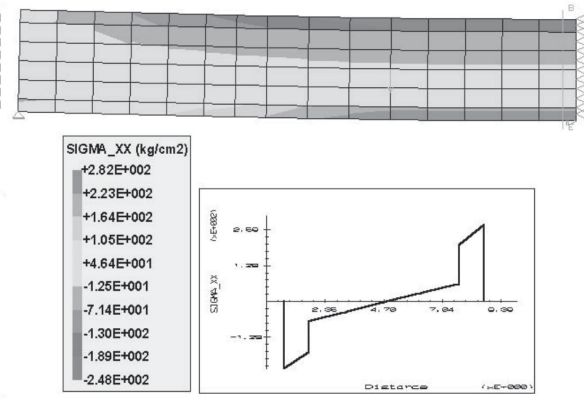

C.

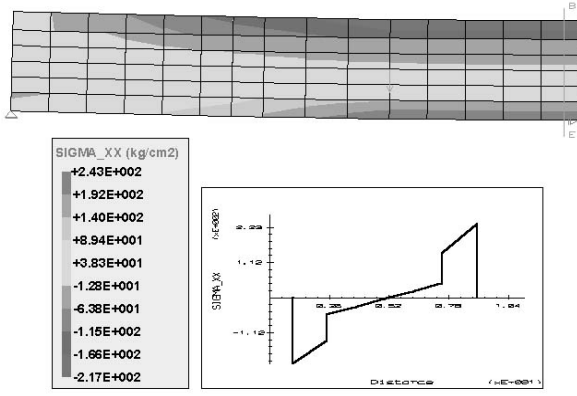

Figura 10. Distribuição das tensões $\sigma_{x}$ para a vigas R1(A), V1(B) e V2(C), referente ao carregamento de 4 kN

giganteus - Pinus elliottii, através do método dos elementos finitos. As vigas analisadas apresentavam dimensões iguais às estudadas experimentalmente, enquanto o reforço de bambu foi, em todos os casos, disposto simetricamente na parte superior e inferior das vigas. A espessura da camada de bambu variou de zero a $0,5 \mathrm{~h}$ e as propriedades mecânicas dos materiais foram aquelas apresentadas nas Tabelas 2 e 3; já nas Figuras 10A, 10B e $10 \mathrm{C}$ apresenta-se a distribuição das tensões $\sigma_{x}$, normal à seção transversal, para as vigas R1, V1 e V2, para o carregamento de $4 \mathrm{kN}$, respectivamente. Observa-se que, devido à variação do módulo de elasticidade dos materiais, as vigas com reforço de bambu apresentam descontinuidade no diagrama de tensão e, ainda, que o núcleo de Pinus elliottii trabalha submetido a tensões relativamente baixas comparadas com as do bambu Dendrocalamus giganteus.

Na Figura 11 tem-se a variação do deslocamento vertical da viga com o aumento da espessura do reforço do bambu para o

A.
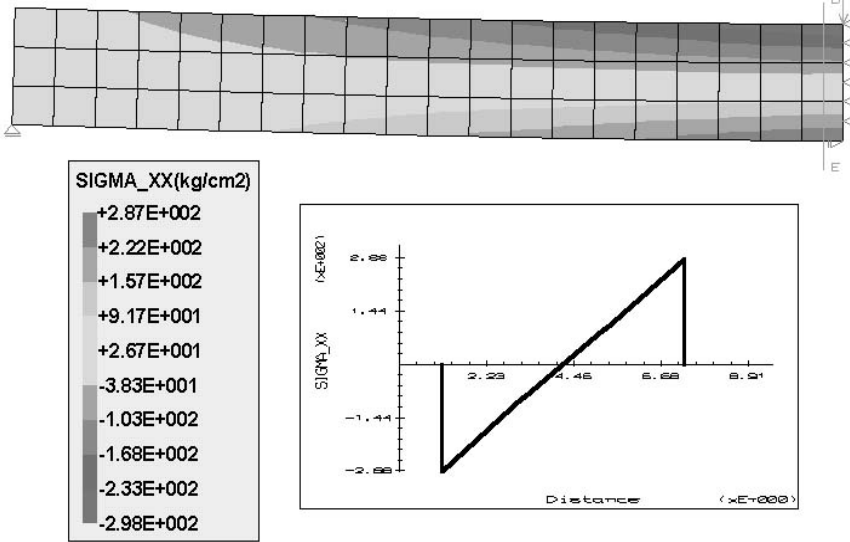

C.
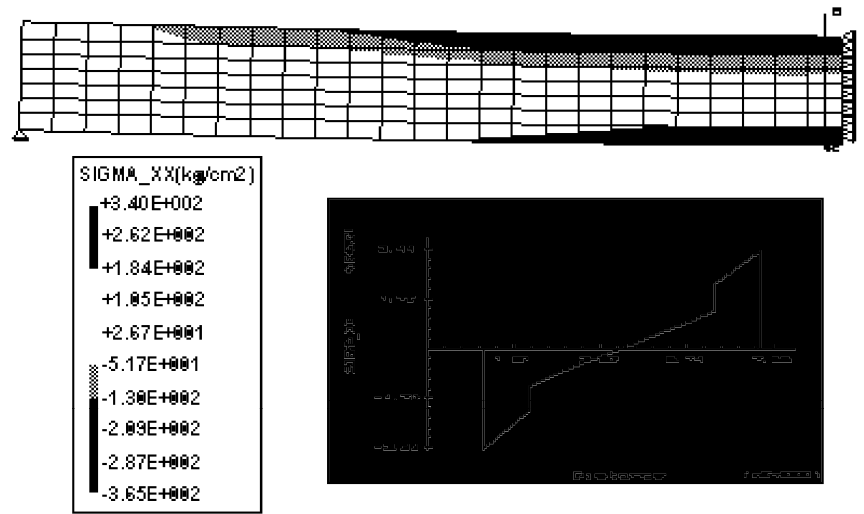

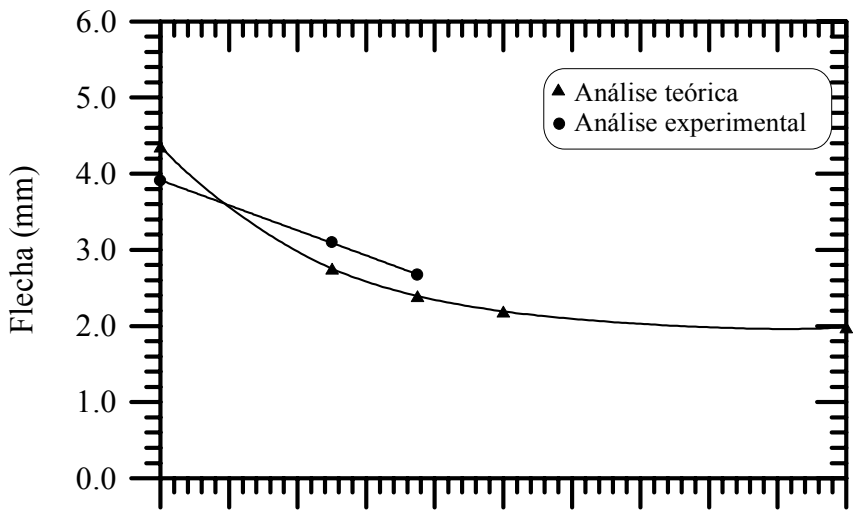

$\begin{array}{llllllllll}0.1 & 0.2 & 0.3 & 0.4 & 0.5 & 0.6 & 0.7 & 0.8 & 0.9 & 1.0\end{array}$ Espessura da camada/Altura

Figura 11. Curva variação do deslocamento vertical vs. espessura relativa de reforço

B.

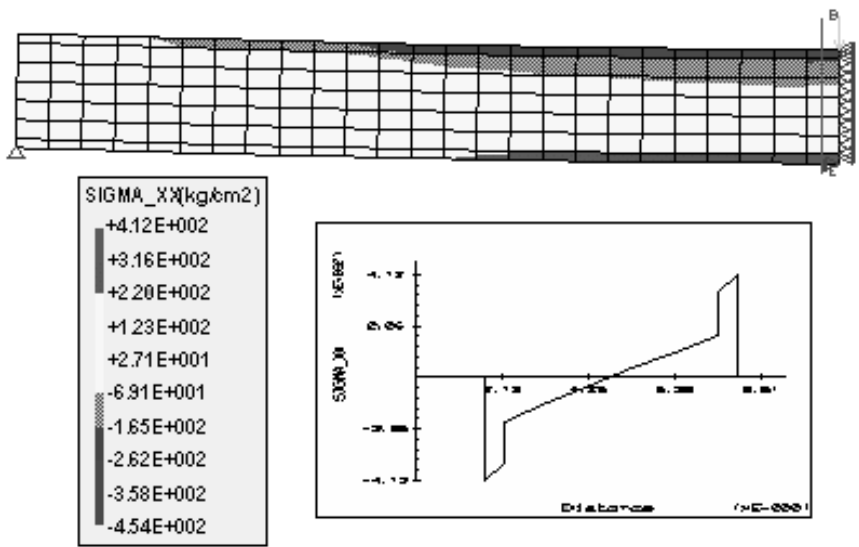

D.
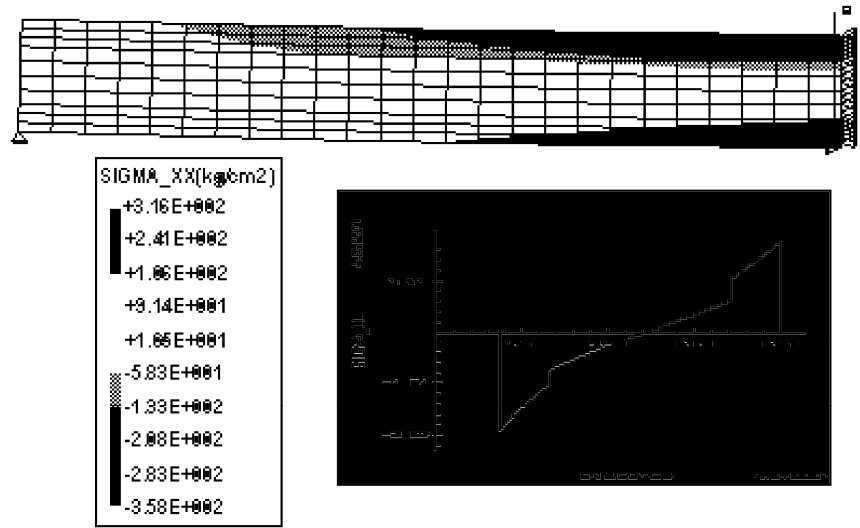

Figura 12. Distribuição das tensões $\sigma_{\mathrm{x}}$ para as vigas R2(A), V3(B), V4(C) e V5(D), referente ao carregamento de 2,5 kN 
carregamento de $4 \mathrm{kN}$. Constata-se diminuição na deflexão da viga, da ordem de $50 \%$, quando o reforço corresponde a $50 \%$ da altura, e de $55 \%$ quando o reforço se relaciona a $100 \%$. Deste modo, vê-se que o comportamento da viga mista é semelhante ao da viga com $100 \%$ de bambu e, também, que o comportamento experimental é similar ao teórico.

O mesmo estudo foi realizado para as vigas da série dois, em que nas Figuras 12A, 12B, 12C e 12D é apresentada a distribuição das tensões $\sigma_{\mathrm{x}}$ para as vigas R2, V3, V4 e V5, para o carregamento de $2,5 \mathrm{kN}$. Novamente, observa-se a mesma descontinuidade no diagrama de tensão.

Na Figura 13 mostra-se a variação do deslocamento vertical da viga com o aumento da espessura do reforço do bambu para o carregamento de $2,5 \mathrm{kN}$, ressaltando-se diminuição na deflexão teórica e experimental da viga, da ordem de 40 e $44 \%$, quando o reforço corresponde a $50 \%$, respectivamente. Nota-se, mais uma vez que, a partir deste ponto, o acréscimo de reforço de bambu leva a um aumento de rigidez pequeno.

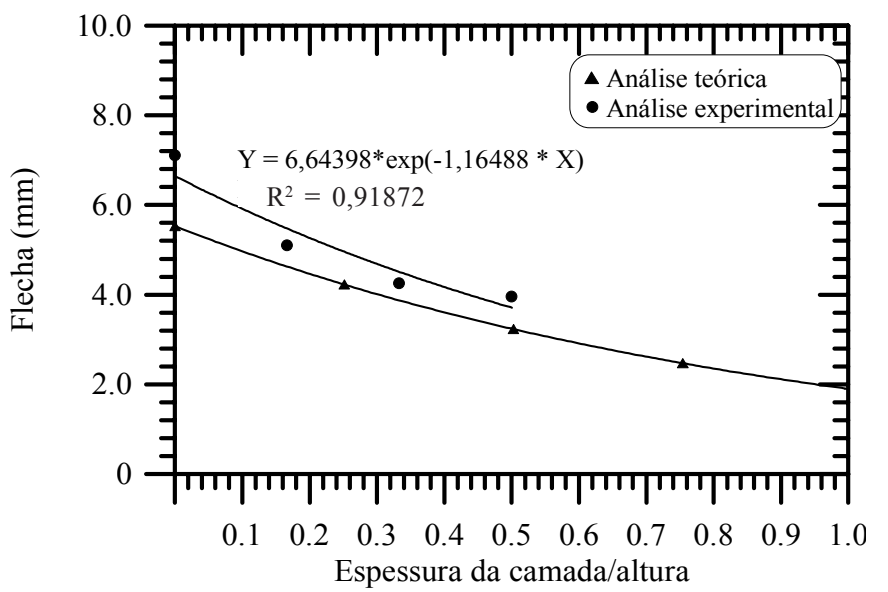

Figura 13. Curva de variação do deslocamento vertical vs. espessura, relativa de reforço

\section{CONCLUSÕES}

1. As vigas laminadas de bambu apresentaram bom desempenho, com ganho de até $70 \%$ de rigidez, quando $33 \%$ da altura da viga de Pinus elliottii foram substituídos por bambu; porém, não se verificou aumento significativo na carga de colapso dos espécimes da série um (R1, V1 e V2), quando da presença do bambu, fato que pode ser explicado, uma vez que o mecanismo de ruptura variou de espécime para espécime.
2. Todas as vigas da série dois (R2, V3, V4 e V5) apresentaram colapsos provocados pela ruptura das tiras de bambu na região nodal, observando-se ganho de carga de $170 \%$, quando $50 \%$ da altura da viga de Pinus elliottii foram substituídos por bambu.

3. O processo de laminação provocou danos na estrutura do bambu na região nodal, comprometendo sua resistência, sendo necessário o aprimoramento deste processo. A tensão média de cisalhamento paralelo às fibras do bambu, foi 7,8 MPa cerca de $30 \%$ inferior à tensão de cisalhamento do Pinus elliottii, que é da ordem de $11 \mathrm{MPa}$.

4. O estudo numérico mostrou boa concordância com os valores experimentais e que o comportamento das vigas mistas bambu-madeira é semelhante as de bambu, tornando aquelas mais atrativas, uma vez que o processo de laminação da madeira é mais simples que o do bambu.

\section{AGRADECIMENTOS}

Os autores agradecem ao Zoológico de Cascavel, PR, pela cessão dos colmos de bambu, e à Coordenação de Aperfeiçoamento de Pessoal de Nível Superior-CAPES, pela concessão de bolsa PICD, ao primeiro autor.

\section{LITERATURA CITADA}

ABNT - Associação Brasileira De Normas Técnicas. Projeto de Estruturas de Madeira - NBR 7190 - anexo B. Rio de Janeiro, 1997, p.132-187.

Bono, C.T. Madeira laminada colada na arquitetura: sistematização de obras executadas no Brasil. São Carlos: EESC/USP, 1996. 365p. Dissertação Mestrado

Culzoni, R.A.M. Características dos bambus e sua utilização como material alternativo no concreto. Rio de Janeiro: PUC, 1986. 215p. Dissertação Mestrado

Lima Jr., H.C.; Dalcanal, P.R.; Willrich, F.L.; Barbosa, N.P. Caracterização teórica-experimental das propriedades mecânicas do Bambu Dendrocalamus giganteus colhido em Cascavel, PR. In: International conference of sustainable construction into the next millenium: Environmentally friendly and innovative cement based materials. João Pessoa, 2000, v.1, p.394-406. 